\title{
Fixed point results for generalized $F$-contractions in modular metric and fuzzy metric spaces
}

\author{
Nawab Hussain ${ }^{1}$, Abdul Latif $^{*}$ and $\mid r a m$ lqbal ${ }^{2}$
}

"Correspondence: alatif@kau.edu.sa 'Department of Mathematics, King Abdulaziz University, P.O. Box 80203, Jeddah, 21589, Saudi Arabia Full list of author information is available at the end of the article

\begin{abstract}
The notion of modular metric space, being a natural generalization of classical modulars over linear spaces, was recently introduced. In this paper, we introduce a generalized $F$-contraction in modular metric space and investigate the existence of fixed points for such contractions. As applications, we derive some new fixed point theorems in partially ordered modular metric spaces, Suzuki type fixed point theorems in modular metric spaces and fixed point theorems for contractions involving integral inequalities. Moreover, we deduce new fixed point results in triangular fuzzy metric spaces and provide some examples to illustrate the usability of the obtained results.
\end{abstract}

Keywords: modular metric space; fixed point; $\alpha$-GF-contraction; $\alpha$ - $\eta$-continuous function; orbitally continuous function

\section{Introduction and preliminaries}

In 1950 [1], Nakano initiated the theory of modular spaces and further it was generalized and redefined by Musielak and Orlicz [2, 3] in 1959. In 2010, Chistyakov introduced the notion of modular metric spaces in $[4,5]$. The main idea behind this new concept is the physical interpretation of the modular. A metric on a set represents nonnegative finite distances between any two points of the set, a modular on a set attributes a nonnegative (possibly, infinite valued) 'field of (generalized) velocities': to each time $\lambda>0$ the absolute value of an average velocity $\omega_{\lambda}(x, y)$ is associated in such a way that in order to cover the distance between points $x, y \in X$ it takes time $\lambda$ to move from $x$ to $y$ with velocity $\omega_{\lambda}(x, y)$. In recent years, there was a strong interest to study the fixed point property in modular function spaces after the first paper [6] was published in 1990. Many mathematicians studied fixed point results for modular metric spaces; see [7-12]. Recently, Wardowski [13] introduced and studied a new contraction, called $F$-contraction, to prove a fixed point result as a generalization of the Banach contraction principle. Hussain and Salimi [14] further generalized the concept of $F$-contraction and introduced an $\alpha$-GF-contraction with respect to a general family of functions $G$ (see also [15-17] and references therein). In this paper, we obtain fixed point results for $\alpha-\eta$-GF-contractions in modular metric and partially ordered modular metric spaces. As an application of our results we deduce Suzuki type results for GF-contractions. We derive fixed and periodic point results for orbitally

(c) 2015 Hussain et al. This article is distributed under the terms of the Creative Commons Attribution 4.0 International License (http://creativecommons.org/licenses/by/4.0/), which permits unrestricted use, distribution, and reproduction in any medium, provided you give appropriate credit to the original author(s) and the source, provide a link to the Creative Commons license, and indicate if changes were made. 
continuous generalized $F$-contractions in modular metric spaces. In the last section, we prove new fixed point results in triangular fuzzy metric spaces.

We begin with some basic definitions and results which will be used in the sequel. Throughout this article, $\mathbb{N}, \mathbb{R}+, \mathbb{R}$ denote the set of all natural numbers, the set of all positive real numbers, and the set of all real numbers, respectively.

Let $X$ be a nonempty set. Throughout this paper for a function $\omega:(0, \infty) \times X \times X \rightarrow$ $[0, \infty]$, we will write

$$
\omega_{\lambda}(x, y)=\omega(\lambda, x, y)
$$

for all $\lambda>0$ and $x, y \in X$.

Definition 1.1 A function $\omega:(0, \infty) \times X \times X \rightarrow[0, \infty]$ is said to be modular metric on $X$ if it satisfies the following axioms:

(1) $x=y$ if and only if $\omega_{\lambda}(x, y)=0$, for all $\lambda>0$;

(2) $\omega_{\lambda}(x, y)=\omega_{\lambda}(y, x)$, for all $\lambda>0$ and $x, y \in X$;

(3) $\omega_{\lambda}(x, y)=\omega_{\lambda}(x, z)+\omega_{\lambda}(z, y)$, for all $\lambda>0$ and $x, y, z \in X$.

Definition 1.2 [18] Let $T$ be a self-mapping on $X$ and $\alpha: X \times X \rightarrow[0,+\infty)$ be a function. We say that $T$ is an $\alpha$-admissible mapping if

$$
x, y \in X, \quad \alpha(x, y) \geq 1 \quad \Longrightarrow \quad \alpha(T x, T y) \geq 1 .
$$

Definition 1.3 [19] Let $T$ be a self-mapping on $X$ and $\alpha, \eta: X \times X \rightarrow[0,+\infty)$ be two functions. We say that $T$ is an $\alpha$-admissible mapping with respect to $\eta$ if

$$
x, y \in X, \quad \alpha(x, y) \geq \eta(x, y) \quad \Longrightarrow \quad \alpha(T x, T y) \geq \eta(T x, T y) .
$$

Note that if we take $\eta(x, y)=1$ then this definition reduces to Definition 1.2. Also, if we take $\alpha(x, y)=1$ then we say that $T$ is an $\eta$-subadmissible mapping.

Definition 1.4 [20] Let $(X, d)$ be a metric space. Let $\alpha, \eta: X \times X \rightarrow[0, \infty)$ be functions. We say $T: X \rightarrow X$ is an $\alpha-\eta$-continuous mapping on $(X, d)$, if, for given $x \in X$ and sequence $\left\{x_{n}\right\}$ with

$$
x_{n} \rightarrow x \quad \text { as } n \rightarrow \infty, \quad \alpha\left(x_{n}, x_{n+1}\right) \geq \eta\left(x_{n}, x_{n+1}\right) \quad \text { for all } n \in \mathbb{N} \quad \Longrightarrow \quad T x_{n} \rightarrow T x .
$$

A mapping $T: X \rightarrow X$ is called orbitally continuous at $p \in X$ if $\lim _{n \rightarrow \infty} T^{n} x=p$ implies that $\lim _{n \rightarrow \infty} T T^{n} x=T p$. The mapping $T$ is orbitally continuous on $X$ if $T$ is orbitally continuous for all $p \in X$. A metric space $X$ is called $T$-orbitally complete if every Cauchy sequence of the form $\left\{T^{n_{i}} x\right\}_{i=1}^{\infty}, x \in X$, converges in $X$.

Remark 1.1 [20] Let $T: X \rightarrow X$ be a self-mapping on an $T$-orbitally complete metric space $X$. Define, $\alpha, \eta: X \times X \rightarrow[0,+\infty)$ by

$$
\alpha(x, y)=\left\{\begin{array}{ll}
3, & \text { if } x, y \in O(w), \\
0, & \text { otherwise }
\end{array} \text { and } \quad \eta(x, y)=1,\right.
$$


where $O(w)=\left\{T^{k} w: k \geq 0\right\}$ is an orbit of a point $w \in X$. If $T: X \rightarrow X$ is an orbitally continuous map on $(X, d)$, then $T$ is $\alpha-\eta$-continuous on $(X, d)$.

\section{Fixed point results for $\alpha$-GF-contractions}

Consistent with Wardowski [13], we denote by $\Delta_{F}$ the set of all functions $F: \mathbb{R}^{+} \rightarrow \mathbb{R}$ satisfying the following conditions:

$\left(\mathrm{F}_{1}\right) F$ is strictly increasing;

$\left(\mathrm{F}_{2}\right)$ for all sequence $\left\{\alpha_{n}\right\} \subseteq \mathbb{R}^{+}, \lim _{n \rightarrow \infty} \alpha_{n}=0$ if and only if $\lim _{n \rightarrow \infty} F\left(\alpha_{n}\right)=-\infty$;

$\left(\mathrm{F}_{3}\right)$ there exist $0<k<1$ such that $\lim _{n \rightarrow 0^{+}} \alpha^{k} F(\alpha)=0$.

Now we introduce the following family of new functions (see also [21]).

Let $\Delta_{G}$ denotes the set of all functions $G: \mathbb{R}^{+^{4}} \rightarrow \mathbb{R}^{+}$satisfying:

(G) for all $t_{1}, t_{t}, t_{3}, t_{4} \in \mathbb{R}^{+}$with $t_{1} t_{2} t_{3} t_{4}=0$ there exists $\tau>0$ such that $G\left(t_{1}, t_{2}, t_{3}, t_{4}\right)=\tau$.

Example 2.1 If $G\left(t_{1}, t_{2}, t_{3}, t_{4}\right)=L \min \left\{t_{1}, t_{2}, t_{3}, t_{4}\right\}+\tau$ where $L \in \mathbb{R}^{+}$and $\tau>0$, then $G \in \Delta_{G}$.

Example 2.2 If $G\left(t_{1}, t_{2}, t_{3}, t_{4}\right)=\tau e^{L \min \left\{t_{1}, t_{2}, t_{3}, t_{4}\right\}}$ where $L \in \mathbb{R}^{+}$and $\tau>0$, then $G \in \Delta_{G}$.

Example 2.3 If $G\left(t_{1}, t_{2}, t_{3}, t_{4}\right)=L \ln \left(\min \left\{t_{1}, t_{2}, t_{3}, t_{4}\right\}+1\right)+\tau$ where $L \in \mathbb{R}^{+}$and $\tau>0$, then $G \in \Delta_{G}$.

Definition 2.1 Let $X_{\omega}$ be a modular metric space and $T$ be a self-mapping on $X_{\omega}$. Suppose that $\alpha, \eta: X_{\omega} \times X_{\omega} \rightarrow[0, \infty)$ be two functions. We say $T$ is an $\alpha-\eta$-GF-contraction if for $x, y \in X_{\omega}$ with $\eta(x, T x) \leq \alpha(x, y), \omega_{\lambda / l}(T x, T y)>0$, and $\lambda>0$ we have

$$
G\left(\omega_{\lambda / l}(x, T x), \omega_{\lambda / l}(y, T y), \omega_{\lambda / l}(x, T y), \omega_{\lambda / l}(y, T x)\right)+F\left(\omega_{\lambda / l}(T x, T y)\right) \leq F\left(\omega_{\lambda / l}(x, y)\right),
$$

where $G \in \Delta_{G}$ and $F \in \Delta_{F}$.

Now we state and prove the main result of this section.

Theorem 2.1 Let $X_{\omega}$ be a complete modular metric space. Let $T: X_{\omega} \rightarrow X_{\omega}$ be a selfmapping satisfying the following assertions:

(i) $T$ is an $\alpha$-admissible mapping with respect to $\eta$;

(ii) there exists $x_{0} \in X_{\omega}$ such that $\alpha\left(x_{0}, T x_{0}\right) \geq \eta\left(x_{0}, T x_{0}\right)$;

(iii) $T$ is an $\alpha-\eta$-continuous function;

(iv) $T$ is an $\alpha-\eta-G F$-contraction.

Then $T$ has a fixed point. Moreover, $T$ has a unique fixed point when $\alpha(x, y) \geq \eta(x, x)$ for all $x, y \in \operatorname{Fix}(T)$.

Proof Let $x_{0} \in X_{\omega}$ such that $\alpha\left(x_{0}, T x_{0}\right) \geq \eta\left(x_{0}, T x_{0}\right)$. For $x_{0} \in X_{\omega}$, we define the sequence $\left\{x_{n}\right\}$ by $x_{n}=T^{n} x_{0}=T x_{n-1}$. Now since $T$ is an $\alpha$-admissible mapping with respect to $\eta$, $\alpha\left(x_{0}, x_{1}\right)=\alpha\left(x_{0}, T x_{0}\right) \geq \eta\left(x_{0}, T x_{0}\right)=\eta\left(x_{0}, x_{1}\right)$. By continuing this process we have

$$
\eta\left(x_{n-1}, T x_{n-1}\right)=\eta\left(x_{n-1}, x_{n}\right) \leq \alpha\left(x_{n-1}, x_{n}\right)
$$

for all $n \in \mathbb{N}$. Also, let there exists $n_{0} \in X$ such that $x_{n_{0}}=x_{n_{0}+1}$. Then $x_{n_{0}}$ is fixed point of $T$ and we have nothing to prove. Hence, we assume, $x_{n} \neq x_{n+1}$ or $\omega_{\lambda / l}\left(T x_{n-1}, T x_{n}\right)>0$ for all 
$n \in \mathbb{N} \cup\{0\}$. Since $T$ is an $\alpha-\eta-G F$-contraction, by taking $x=x_{n-1}$ and $y=x_{n}$ in (2.1), we get

$$
\begin{aligned}
& G\left(\omega_{\lambda / l}\left(x_{n-1}, T x_{n-1}\right), \omega_{\lambda / l}\left(x_{n}, T x_{n}\right), \omega_{\lambda / l}\left(x_{n-1}, T x_{n}\right), \omega_{\lambda / l}\left(x_{n}, T x_{n-1}\right)\right)+F\left(\omega_{\lambda / l}\left(T x_{n-1}, T x_{n}\right)\right) \\
& \quad \leq F\left(\omega_{\lambda / l}\left(x_{n-1}, x_{n}\right)\right),
\end{aligned}
$$

which implies

$$
\begin{aligned}
& G\left(\omega_{\lambda / l}\left(x_{n-1}, x_{n}\right), \omega_{\lambda / l}\left(x_{n}, x_{n+1}\right), \omega_{\lambda / l}\left(x_{n-1}, x_{n+1}\right), \omega_{\lambda / l}\left(x_{n}, x_{n}\right)\right)+F\left(\omega_{\lambda / l}\left(x_{n}, x_{n+1}\right)\right) \\
& \quad \leq F\left(\omega_{\lambda / l}\left(x_{n-1}, x_{n}\right)\right) .
\end{aligned}
$$

So,

$$
G\left(\omega_{\lambda / l}\left(x_{n-1}, x_{n}\right), \omega_{\lambda / l}\left(x_{n}, x_{n+1}\right), \omega_{\lambda / l}\left(x_{n-1}, x_{n+1}\right), 0\right)+F\left(\omega_{\lambda / l}\left(x_{n}, x_{n+1}\right)\right) \leq F\left(\omega_{\lambda / l}\left(x_{n-1}, x_{n}\right)\right) .
$$

Now since $\omega_{\lambda / l}\left(x_{n-1}, x_{n}\right) \cdot \omega_{\lambda} \lambda / l\left(x_{n}, x_{n+1}\right) . \omega_{\lambda / l}\left(x_{n-1}, x_{n+1}\right) .0=0$, so from (G) there exists $\tau>0$ such that

$$
G\left(\omega_{\lambda / l}\left(x_{n-1}, x_{n}\right), \omega_{\lambda / l}\left(x_{n}, x_{n+1}\right), \omega_{\lambda / l}\left(x_{n-1}, x_{n+1}\right), 0\right)=\tau
$$

From (2.2) we deduce that

$$
F\left(\omega_{\lambda / l}\left(x_{n}, x_{n+1}\right)\right) \leq F\left(\omega_{\lambda / l}\left(x_{n-1}, x_{n}\right)\right)-\tau
$$

Therefore,

$$
\begin{aligned}
F\left(\omega_{\lambda / l}\left(x_{n}, x_{n+1}\right)\right) & \leq F\left(\omega_{\lambda / l}\left(x_{n-1}, x_{n}\right)\right)-\tau \leq F\left(\omega_{\lambda / l}\left(x_{n-2}, x_{n-1}\right)\right)-2 \tau \leq \cdots \\
& \leq F\left(\omega_{\lambda / l}\left(x_{0}, x_{1}\right)\right)-n \tau .
\end{aligned}
$$

So,

$$
F\left(\omega_{\lambda / l}\left(x_{n}, x_{n+1}\right)\right) \leq F\left(\omega_{\lambda}\left(x_{0}, x_{1}\right)\right)-n \tau
$$

By taking the limit as $n \rightarrow \infty$ in (2.3) we have $F\left(\omega_{\lambda}\left(x_{n}, x_{n+1}\right)\right) \rightarrow-\infty$ and since $F \in \Delta_{F}$ we obtain

$$
\lim _{n \rightarrow \infty} \omega_{\lambda / l}\left(x_{n}, x_{n+1}\right)=0
$$

So, for each $\lambda>0$, we see, for all $\epsilon>0$, that there exists $n_{0} \in \mathbb{N}$ such that

$$
\omega_{\lambda / l}\left(x_{n}, x_{n+1}\right)<\epsilon,
$$

for all $n \in \mathbb{N}$ with $n \geq n_{0}$. Without loss of generality, suppose $m, n \in \mathbb{N}$ and $m>n$. Observe that, for $\frac{\lambda}{l(m-n)}>0$, there exists $n_{\frac{\lambda}{(m-n)}} \in \mathbb{N}$ such that

$$
\omega \frac{\lambda}{l(m-n)}\left(x_{n}, x_{n+1}\right)<\frac{\epsilon}{l(m-n)}
$$


for all $n \geq n_{\frac{\lambda}{(m-n)}}$. Now, we have

$$
\begin{aligned}
\omega_{\lambda / l}\left(x_{n}, x_{m}\right) & \leq \omega_{\frac{\lambda}{l(m-n)}}\left(x_{n}, x_{n+1}\right)+\omega_{\frac{\lambda}{l(m-n)}}\left(x_{n+1}, x_{n+2}\right)+\cdots+\omega_{\frac{\lambda}{l(m-n)}}\left(x_{m-1}, x_{m}\right) \\
& <\frac{\epsilon}{l(m-n)}+\frac{\epsilon}{l(m-n)}+\cdots+\frac{\epsilon}{l(m-n)} \\
& =\epsilon / l,
\end{aligned}
$$

for all $m, n \geq n \frac{\lambda}{(m-n)}$. This shows that $\left\{x_{n}\right\}$ is a Cauchy sequence. Since $X_{\omega}$ is complete, there exists $x^{*} \in X_{\omega}$ such that $x_{n} \rightarrow x^{*}$ as $n \rightarrow \infty$. Now since $T$ is an $\alpha-\eta$-continuous and $\eta\left(x_{n-1}, x_{n}\right) \leq \alpha\left(x_{n-1}, x_{n}\right), x_{n+1}=T x_{n} \rightarrow T x^{*}$ as $n \rightarrow \infty$. Therefore,

$$
T x^{*}=\lim _{n \rightarrow \infty} T x_{n}=\lim _{n \rightarrow \infty} x_{n+1}=x^{*} .
$$

Thus $T$ has a fixed point. Now let $x, y \in \operatorname{Fix}(T)$ where $x \neq y$. Then

$$
\begin{aligned}
& G\left(\omega_{\lambda / l}(x, T x), \omega_{\lambda / l}(y, T y), \omega_{\lambda / l}(x, T y), \omega_{\lambda / l}(y, T x)\right)+F\left(\omega_{\lambda / l}(T x, T y)\right) \leq F\left(\omega_{\lambda / l}(x, y)\right), \\
& G\left(0,0, \omega_{\lambda / l}(x, T y), \omega_{\lambda / l}(y, T x)\right)+F\left(\omega_{\lambda / l}(T x, T y)\right) \leq F\left(\omega_{\lambda / l}(x, y)\right),
\end{aligned}
$$

so there exists $\tau>0$ such that

$$
G\left(0,0, \omega_{\lambda / l}(x, T y), \omega_{\lambda / l}(y, T x)\right)+F\left(\omega_{\lambda / l}(T x, T y)\right)=\tau
$$

We get

$$
\tau+F\left(\omega_{\lambda / l}(T x, T y)\right) \leq F\left(\omega_{\lambda / l}(x, y)\right)
$$

which is a contradiction. Hence, $x=y$. Therefore, $T$ has a unique fixed point.

Combining Theorem 2.1 and Example 2.1 we deduce the following corollary.

Corollary 2.1 Let $X_{\omega}$ be a complete modular metric space and $T: X_{\omega} \rightarrow X_{\omega}$ be a selfmapping satisfying the following assertions:

(i) $T$ is an $\alpha$-admissible mapping with respect to $\eta$;

(ii) iffor $x, y \in X$ with $\eta(x, T x) \leq \alpha(x, y)$ and $\omega_{\lambda / l}(T x, T y)>0$ we have

$$
\tau+F\left(\omega_{\lambda / l}(T x, T y)\right) \leq F\left(\omega_{\lambda / l}(x, y)\right)
$$

where $\tau>0$ and $F \in \Delta_{F}$;

(iii) there exists $x_{0} \in X$ such that $\alpha\left(x_{0}, T x_{0}\right) \geq \eta\left(x_{0}, T x_{0}\right)$;

(iv) $T$ is an $\alpha-\eta$-continuous function.

Then $T$ has a fixed point. Moreover, $T$ has a unique fixed point when $\alpha(x, y) \geq \eta(x, y)$ for all $x, y \in \operatorname{Fix}(T)$.

Example 2.4 Let $X=[0,1]$ and $\omega_{\lambda}(x, y)=(1 / \lambda)|x-y|$. Define, $T: X_{\omega} \rightarrow X_{\omega}, \alpha, \eta: X_{\omega} \times$ $X_{\omega} \rightarrow[0, \infty), G: \mathbb{R}^{+^{4}} \rightarrow \mathbb{R}^{+}$and $F: \mathbb{R}^{+} \rightarrow \mathbb{R}$ by 


$$
T x= \begin{cases}\frac{1}{2} e^{-\tau} x, & \text { if } x \text { is rational } \\ \frac{1}{3} e^{-\tau} x & \text { if } x \text { is irrational, }\end{cases}
$$

$\alpha(x, y)=x+y$ and $\eta(x, y)=\frac{x+y}{2}, G\left(t_{1}, t_{2}, t_{3}, t_{4}\right)=\tau$ where $\tau>0$ and $F(r)=\ln r$.

Let $\alpha(x, y) \geq \eta(x, y)$, then $x, y \in[0,1]$. On the other hand, $T w \in[0,1]$ for all $w \in[0,1]$.

Then $\alpha(T x, T y) \geq \eta(T x, T y)$. That is, $T$ is an $\alpha$-admissible mapping with respect to $\eta$.

Case I: $x$ and $y$ both are rational.

Let $\alpha(x, y) \geq \eta(x, T x)$, then

$$
\omega_{\lambda / l}(T x, T y)=\frac{l}{2 \lambda} e^{-\tau}|x-y| \leq \frac{l}{\lambda} e^{-\tau}|x-y|=e^{-\tau} \omega_{\lambda / l}(x, y),
$$

which implies

$$
\begin{aligned}
F\left(\omega_{\lambda / l}(T x, T y)\right) & =\ln \omega_{\lambda / l}(T x, T y) \\
& \leq \ln e^{-\tau} \omega_{\lambda / l}(x, y) \\
& =-\tau+\ln \omega_{\lambda / l}(x, y) \\
& =-\tau+F\left(\omega_{\lambda / l}(x, y)\right) .
\end{aligned}
$$

Hence

$$
\tau+F\left(\omega_{\lambda / l}(T x, T y)\right) \leq F\left(\omega_{\lambda / l}(x, y)\right) .
$$

Hence, $T$ is an $\alpha-\eta-G F$-contraction mapping.

Case II: $x$ and $y$ both are irrational.

Let $\alpha(x, y) \geq \eta(x, T x)$, then

$$
\omega_{\lambda / l}(T x, T y)=\frac{l}{3 \lambda} e^{-\tau}|x-y| \leq \frac{l}{\lambda} e^{-\tau}|x-y|=e^{-\tau} \omega_{\lambda / l}(x, y),
$$

which implies

$$
\begin{aligned}
F\left(\omega_{\lambda / l}(T x, T y)\right) & =\ln \omega_{\lambda / l}(T x, T y) \\
& \leq \ln e^{-\tau} \omega_{\lambda / l}(x, y) \\
& =-\tau+\ln \omega_{\lambda / l}(x, y) \\
& =-\tau+F\left(\omega_{\lambda / l}(x, y)\right) .
\end{aligned}
$$

Hence

$$
\tau+F\left(\omega_{\lambda / l}(T x, T y)\right) \leq F\left(\omega_{\lambda / l}(x, y)\right) .
$$

Hence, $T$ is an $\alpha-\eta-G F$-contraction mapping.

Case III: $x$ is rational and $y$ is irrational.

Let $\alpha(x, y) \geq \eta(x, T x)$, then

$$
\omega_{\lambda / l}(T x, T y)=\frac{l}{\lambda} e^{-\tau}\left|\frac{x}{2}-\frac{y}{3}\right| \leq \frac{l}{\lambda} e^{-\tau}|x-y|=e^{-\tau} \omega_{\lambda / l}(x, y),
$$


which implies

$$
\begin{aligned}
F\left(\omega_{\lambda / l}(T x, T y)\right) & =\ln \omega_{\lambda / l}(T x, T y) \\
& \leq \ln e^{-\tau} \omega_{\lambda / l}(x, y) \\
& =-\tau+\ln \omega_{\lambda / l}(x, y) \\
& =-\tau+F\left(\omega_{\lambda / l}(x, y)\right) .
\end{aligned}
$$

Hence

$$
\tau+F\left(\omega_{\lambda / l}(T x, T y)\right) \leq F\left(\omega_{\lambda / l}(x, y)\right) .
$$

Hence, $T$ is an $\alpha-\eta-G F$-contraction mapping. Thus all conditions of Theorem 2.1 hold and note that 0 is a fixed point of $T$.

Theorem 2.2 Let $X_{\omega}$ be a complete modular metric space. Let $T: X_{\omega} \rightarrow X_{\omega}$ be a selfmapping satisfying the following assertions:

(i) $T$ is an $\alpha$-admissible mapping with respect to $\eta$;

(ii) there exists $x_{0} \in X_{\omega}$ such that $\alpha\left(x_{0}, T x_{0}\right) \geq \eta\left(x_{0}, T x_{0}\right)$;

(iii) if $\left\{x_{n}\right\}$ is a sequence in $X_{\omega}$ such that $\alpha\left(x_{n}, x_{n+1}\right) \geq \eta\left(x_{n}, x_{n+1}\right)$ with $x_{n} \rightarrow x$ as $n \rightarrow \infty$, then either

$$
\eta\left(T x_{n}, T^{2} x_{n}\right) \leq \alpha\left(T x_{n}, x\right) \quad \text { or } \quad \eta\left(T^{2} x_{n}, T^{3} x_{n}\right) \leq \alpha\left(T^{2} x_{n}, x\right)
$$

holds for all $n \in \mathbb{N}$;

(iv) $T$ is an $\alpha-\eta$-GF-contraction.

Then $T$ has a fixed point. Moreover, $T$ has a unique fixed point whenever $\alpha(x, y) \geq \eta(x, x)$ for all $x, y \in \operatorname{Fix}(T)$.

Proof Let $x_{0} \in X_{\omega}$ such that $\alpha\left(x_{0}, T x_{0}\right) \geq \eta\left(x_{0}, T x_{0}\right)$. As in proof of Theorem 2.1 we can deduce a sequence $\left\{x_{n}\right\}$ such that $x_{n+1}=T x_{n}$ with

$$
\alpha\left(x_{n}, x_{n+1}\right) \geq \eta\left(x_{n}, x_{n+1}\right)
$$

and there exists $x^{*} \in X_{\omega}$ such that $x_{n} \rightarrow x^{*}$ as $n \rightarrow \infty$. So, from (iii), either

$$
\eta\left(T x_{n}, T^{2} x_{n}\right) \leq \alpha\left(T x_{n}, x^{*}\right) \quad \text { or } \quad \eta\left(T^{2} x_{n}, T^{3} x_{n}\right) \leq \alpha\left(T^{2} x_{n}, x^{*}\right)
$$

holds for all $n \in \mathbb{N}$. This implies

$$
\eta\left(x_{n+1}, x_{n+2}\right) \leq \alpha\left(x_{n+1}, x\right) \quad \text { or } \quad \eta\left(x_{n+2}, x_{n+3}\right) \leq \alpha\left(x_{n+2}, x\right)
$$

holds for all $n \in \mathbb{N}$. Let $\eta\left(x_{n+1}, x_{n+2}\right) \leq \alpha\left(x_{n+1}, x\right)$, equivalently, there exists a subsequence $\left\{x_{n_{k}}\right\}$ of $\left\{x_{n}\right\}$ such that

$$
\eta\left(x_{n_{k}}, T x_{n_{k}}\right)=\eta\left(x_{n_{k}}, x_{n_{k}+1}\right) \leq \alpha\left(x_{n_{k}}, x^{*}\right)
$$


and so from (2.1) for $x=x_{n_{k}}$ and $y=x^{*}$, we deduce that

$$
\begin{aligned}
& G\left(\omega_{\lambda / l}\left(x_{n_{k}}, T x_{n_{k}}\right), \omega_{\lambda / l}\left(x^{*}, T x^{*}\right), \omega_{\lambda / l}\left(x_{n_{k}}, T x^{*}\right), \omega_{\lambda / l}\left(x^{*}, T x_{n_{k}}\right)\right)+F\left(\omega_{\lambda / l}\left(T x_{n_{k}}, T x^{*}\right)\right) \\
& \quad \leq F\left(\omega_{\lambda / l}\left(x_{n_{k}}, x^{*}\right)\right),
\end{aligned}
$$

which implies

$$
F\left(\omega_{\lambda / l}\left(T x_{n_{k}}, T x^{*}\right)\right) \leq F\left(\omega_{\lambda / l}\left(x_{n_{k}}, x^{*}\right)\right) .
$$

From (F1) we have

$$
\omega_{\lambda / l}\left(x_{n_{k}+1}, T x^{*}\right)<\omega_{\lambda / l}\left(x_{n_{k}}, x^{*}\right)
$$

By taking the limit as $k \rightarrow \infty$ in the above inequality we get

$$
\omega_{\lambda / l}\left(x^{*}, T x^{*}\right)=\omega_{\lambda / l}\left(x^{*}, x^{*}\right)
$$

which is possible only when

$$
\omega_{\lambda / l}\left(x^{*}, T x^{*}\right)=0,
$$

i.e., $x^{*}=T x^{*}$. Similarly we can deduce that $x^{*}=T x^{*}$ when $\eta\left(x_{n+2}, x_{n+3}\right) \leq \alpha\left(x_{n+2}, x\right)$. Uniqueness follows similarly to Theorem 2.1 .

If in Theorem 2.2 we take $\alpha(x, y)=\eta(x, y)=1$ for all $x, y \in X$, then we deduce the main result of Wardowski [13], Theorem 2.1, in the set up of modular metric spaces.

Corollary 2.2 Let $X_{\omega}$ be a complete modular metric space and $T: X_{\omega} \rightarrow X_{\omega}$ be a selfmapping satisfying for $x, y \in X$ with $\omega_{\lambda / l}(T x, T y)>0$ we have

$$
\tau+F\left(\omega_{\lambda / l}(T x, T y)\right) \leq F\left(\omega_{\lambda / l}(x, y)\right)
$$

where $\tau>0$ and $F \in \Delta_{F}$. Then $T$ has a unique fixed point.

Recall that a self-mapping $T$ is said to have the property $P$ if $\operatorname{Fix}\left(T^{n}\right)=F(T)$ for every $n \in \mathbb{N}$.

Theorem 2.3 Let $X_{\omega}$ be a complete modular metric space and $T: X_{\omega} \rightarrow X_{\omega}$ be an $\alpha$ continuous self-mapping. Assume that there exists $\tau>0$ such that

$$
\tau+F\left(\omega_{\lambda / l}\left(T x, T^{2} x\right)\right) \leq F\left(\omega_{\lambda / l}(x, T x)\right)
$$

holds for all $x \in X_{\omega}$ with $\omega_{\lambda / l}\left(T x, T^{2} x\right)>0$ where $F \in \Delta_{F}$. If $T$ is an $\alpha$-admissible mapping and there exists $x_{0} \in X_{\omega}$ such that $\alpha\left(x_{0}, T x_{0}\right) \geq 1$, then $T$ has the property $P$. 
Proof Let $x_{0} \in X_{\omega}$ such that $\alpha\left(x_{0}, T x_{0}\right) \geq 1$. For $x_{0} \in X_{\omega}$, we define the sequence $\left\{x_{n}\right\}$ by $x_{n}=T^{n} x_{0}=T x_{n}$. Now since $T$ is an $\alpha$-admissible mapping, so $\alpha\left(x_{1}, x_{2}\right)=\alpha\left(T x_{0}, T x_{1}\right) \geq 1$. By continuing this process we have

$$
\alpha\left(x_{n-1}, x_{n}\right) \geq 1
$$

for all $n \in \mathbb{N}$. If there exists $n_{0} \in \mathbb{N}$ such that $x_{n_{0}}=x_{n_{0}+1}=T x_{n_{0}}$, then $x_{n_{0}}$ is fixed point of $T$ and we have nothing to prove. Hence, we assume, $x_{n} \neq x_{n+1}$ or $\omega_{\lambda / l}\left(T x_{n-1}, T^{2} x_{n-1}\right)>0$ for all $n \in \mathbb{N} \cup\{0\}$. From (2.8) we have

$$
\tau+F\left(\omega_{\lambda / l}\left(T x_{n-1}, T^{2} x_{n-1}\right)\right) \leq F\left(\omega_{\lambda / l}\left(x_{n-1}, T x_{n-1}\right)\right)
$$

which implies

$$
\tau+F\left(\omega_{\lambda / l}\left(x_{n}, x_{n+1}\right)\right) \leq F\left(\omega_{\lambda / l}\left(x_{n-1}, x_{n}\right)\right)
$$

and so

$$
F\left(\omega_{\lambda / l}\left(x_{n}, x_{n+1}\right)\right) \leq F\left(\omega_{\lambda / l}\left(x_{n-1}, x_{n}\right)\right)-\tau .
$$

Therefore,

$$
\begin{aligned}
F\left(\omega_{\lambda / l}\left(x_{n}, x_{n+1}\right)\right) & \leq F\left(\omega_{\lambda / l}\left(x_{n-1}, x_{n}\right)\right)-\tau \leq F\left(\omega_{\lambda / l}\left(x_{n-2}, x_{n-1}\right)\right)-2 \tau \leq \cdots \\
& \leq F\left(\omega_{\lambda / l}\left(x_{0}, x_{1}\right)\right)-n \tau .
\end{aligned}
$$

By taking the limit as $n \rightarrow \infty$ in $(2.10)$ we have $\lim _{n \rightarrow \infty} F\left(\omega_{\lambda / l}\left(x_{n}, x_{n+1}\right)\right)=-\infty$, and since $F \in \Delta_{F}$ we obtain

$$
\lim _{n \rightarrow \infty} \omega_{\lambda / l}\left(x_{n}, x_{n+1}\right)=0 .
$$

So, for each $\lambda>0$, we see, for all $\epsilon>0$, that there exists $n_{0} \in \mathbb{N}$ such that

$$
\omega_{\lambda / l}\left(x_{n}, x_{n+1}\right)<\epsilon,
$$

for all $n \in \mathbb{N}$ with $n \geq n_{0}$. Without loss of generality, suppose $m, n \in \mathbb{N}$ and $m>n$. Observe that for $\frac{\lambda}{l(m-n)}>0$, there exists $n_{\frac{\lambda}{(m-n)}} \in \mathbb{N}$ such that

$$
\omega_{\frac{\lambda}{l(m-n)}}\left(x_{n}, x_{n+1}\right)<\frac{\epsilon}{l(m-n)}
$$

for all $n \geq n_{\frac{\lambda}{m-n}}$. Now, we have

$$
\begin{aligned}
\omega_{\lambda / l}\left(x_{n}, x_{m}\right) & \leq \omega_{\frac{\lambda}{l(m-n)}}\left(x_{n}, x_{n+1}\right)+\omega_{\frac{\lambda}{l(m-n)}}\left(x_{n+1}, x_{n+2}\right)+\cdots+\omega_{\frac{\lambda}{l(m-n)}}\left(x_{m-1}, x_{m}\right) \\
& <\frac{\epsilon}{l(m-n)}+\frac{\epsilon}{l(m-n)}+\cdots+\frac{\epsilon}{l(m-n)} \\
& =\epsilon / l,
\end{aligned}
$$


for all $m, n \geq n_{\frac{\lambda}{m-n}}$. Thus we proved that $\left\{x_{n}\right\}$ is a Cauchy sequence. Completeness of $X_{\omega}$ ensures that there exists $x^{*} \in X_{\omega}$ such that $x_{n} \rightarrow x^{*}$ as $n \rightarrow \infty$. Now since $T$ is $\alpha$ continuous and $\alpha\left(x_{n-1}, x_{n}\right) \geq 1, x_{n+1}=T x_{n} \rightarrow T x^{*}$ as $n \rightarrow \infty$. That is, $x^{*}=T x^{*}$. Thus $T$ has a fixed point and $F\left(T^{n}\right)=F(T)$ for $n=1$. Let $n>1$. Assume contrarily that $z \in F\left(T^{n}\right)$ and $z \notin F(T)$. Then $\omega_{\lambda / l}(z, T z)>0$. Now we have

$$
\begin{aligned}
F\left(\omega_{\lambda / l}(z, T z)\right) & =F\left(\omega_{\lambda / l}\left(T\left(T^{n-1} z\right)\right), T^{2}\left(T^{n-1} z\right)\right) \\
& \leq F\left(\omega_{\lambda / l}\left(T^{n-1} z\right), T^{n} z\right)-\tau \\
& \leq F\left(\omega_{\lambda / l}\left(T^{n-2} z\right), T^{n-1} z\right)-2 \tau \leq \cdots \\
& \leq \omega_{\lambda / l}(z, T z)-n \tau .
\end{aligned}
$$

By taking the limit as $n \rightarrow \infty$ in the above inequality we have $F\left(\omega_{\lambda / l}(z, T z)\right)=-\infty$. Hence, by (F2) we get $\omega_{\lambda / l}(z, T z)=0$, which is a contradiction. Therefore, $F\left(T^{n}\right)=F(T)$ for all $n \in \mathbb{N}$.

Let $\left(X_{\omega}, \preceq\right)$ be a partially ordered modular metric space. Recall that $T: X_{\omega} \rightarrow X \omega$ is nondecreasing if $\forall x, y \in X, x \preceq y \Rightarrow T(x) \preceq T(y)$. Fixed point theorems for monotone operators in ordered metric spaces are widely investigated and have found various applications in differential and integral equations (see [20, 22-26] and references therein). From Theorems 2.1-2.3, we derive the following new results in partially ordered modular metric spaces.

Theorem 2.4 Let $\left(X_{\omega}, \preceq\right)$ be a complete partially ordered modular metric space. Assume that the following assertions hold true:

(i) $T$ is nondecreasing and ordered GF-contraction;

(ii) there exists $x_{0} \in X$ such that $x_{0} \preceq T x_{0}$;

(iii) either for a given $x \in X$ and sequence $\left\{x_{n}\right\}$

$$
x_{n} \rightarrow x \text { as } n \rightarrow \infty \text { and } x_{n} \preceq x_{n+1} \text { for all } n \in \mathbb{N} \text { we have } T x_{n} \rightarrow T x
$$

or if $\left\{x_{n}\right\}$ is a sequence such that $x_{n} \preceq x_{n+1}$ with $x_{n} \rightarrow x$ as $n \rightarrow \infty$, then either

$$
T x_{n} \preceq x \text { or } \quad T^{2} x_{n} \preceq x
$$

holds for all $n \in \mathbb{N}$.

Then $T$ has a fixed point.

Theorem 2.5 Let $\left(X_{\omega}, \preceq\right)$ be a complete partially ordered modular metric space. Assume that the following assertions hold true:

(i) $T$ is nondecreasing and satisfies (2.8) for all $x \in X$ with $\omega_{\lambda / l}\left(T x, T^{2} x\right)>0$ where $F \in \Delta_{F}$ and $\tau>0$;

(ii) there exists $x_{0} \in X$ such that $x_{0} \preceq T x_{0}$;

(iii) $T$ is continuous.

Then $T$ has a property $P$. 


\section{Suzuki-Wardowski type fixed point results}

In this section, as an application of our results proved above, we deduce certain SuzukiWardowski type fixed point theorems. For related work of Suzuki we refer to [27, 28].

Theorem 3.1 Let $X_{\omega}$ be a complete modular metric space and $T$ be a continuous selfmapping on $X_{\omega}$. Assume for $x, y \in X$ with $\omega_{\lambda / l}(x, T x) \leq \omega_{\lambda / l}(x, y)$ and $\omega_{\lambda / l}(T x, T y)>0$ we have

$$
G\left(\omega_{\lambda / l}(x, T x), \omega_{\lambda / l}(y, T y), \omega_{\lambda / l}(x, T y), \omega_{\lambda / l}(y, T x)\right)+F\left(\omega_{\lambda / l}(T x, T y)\right) \leq F\left(\omega_{\lambda / l}(x, y)\right),
$$

where $G \in \Delta_{G}$ and $F \in \Delta_{F}$. Then $T$ has a unique fixed point.

Proof Define, $\alpha, \eta: X \times X \rightarrow[0, \infty)$ by

$$
\alpha(x, y)=\omega_{\lambda / l}(x, y) \quad \text { and } \quad \eta(x, y)=\omega_{\lambda / l}(x, y)
$$

for all $x, y \in X$. Clearly, $\eta(x, y) \leq \alpha(x, y)$ for all $x, y \in X$. That is, conditions (i) and (iii) of Theorem 2.1 hold true. Since $T$ is continuous, $T$ is $\alpha-\eta$-continuous. Let $\eta(x, T x) \leq \alpha(x, y)$ with $\omega_{\lambda / l}(T x, T y)>0$. Equivalently, if $\omega_{\lambda / l}(x, T x) \leq \omega_{\lambda / l}(x, y)$ with $\omega_{\lambda / l}(T x, T y)>0$, then, from (3.1), we have

$$
G\left(\omega_{\lambda / l}(x, T x), \omega_{\lambda / l}(y, T y), \omega_{\lambda / l}(x, T y), \omega_{\lambda / l}(y, T x)\right)+F\left(\omega_{\lambda / l}(T x, T y)\right) \leq F\left(\omega_{\lambda / l}(x, y)\right) .
$$

That is, $T$ is an $\alpha-\eta-G F$-contraction mapping. Hence, all conditions of Theorem 2.1 hold and $T$ has a unique fixed point.

Corollary 3.1 Let $X_{\omega}$ be a complete modular metric space and $T$ be a continuous selfmapping on $X$. If for $x, y \in X$ with $\omega_{\lambda / l}(x, T x) \leq \omega_{\lambda / l}(x, y)$ and $\omega_{\lambda / l}(T x, T y)>0$ we have

$$
\tau+F\left(\omega_{\lambda / l}(T x, T y)\right) \leq F\left(\omega_{\lambda / l}(x, y)\right)
$$

where $\tau>0$ and $F \in \Delta_{F}$, then $T$ has a unique fixed point.

Corollary 3.2 Let $X_{\omega}$ be a complete metric space and $T$ be a continuous self-mapping on $X$. Assume for $x, y \in X$ with $\omega_{\lambda / l}(x, T x) \leq \omega_{\lambda / l}(x, y)$ and $\omega_{\lambda / l}(T x, T y)>0$ we have

$$
\tau e^{L \min \left\{\omega_{\lambda / l}(x, T x), \omega_{\lambda / l}(y, T y), \omega_{\lambda / l}(x, T y), \omega_{\lambda / l}(y, T x)\right\}}+F\left(\omega_{\lambda / l}(T x, T y)\right) \leq F\left(\omega_{\lambda / l}(x, y)\right),
$$

where $\tau>0, L \geq 0$, and $F \in \Delta_{F}$. Then $T$ has a unique fixed point.

Theorem 3.2 Let $X_{\omega}$ be a complete modular metric space and $T$ be a self-mapping on $X$. Assume that there exists $\tau>0$ such that

$$
\frac{1}{2(1+\tau)} \omega_{\lambda / l}(x, T x) \leq \omega_{\lambda / 2 l}(x, y) \quad \text { implies } \quad \tau+F\left(\omega_{\lambda / l}(T x, T y)\right) \leq F\left(\omega_{\lambda / l}(x, y)\right)
$$

for $x, y \in X$ with $\omega_{\lambda / l}(T x, T y)>0$ where $F \in \Delta_{F}$. Then $T$ has a unique fixed point. 
Proof Define, $\alpha, \eta: X \times X \rightarrow[0, \infty)$ by

$$
\alpha(x, y)=\omega_{\lambda / 2 l}(x, y) \quad \text { and } \quad \eta(x, y)=\frac{1}{2(1+\tau)} \omega_{\lambda / l}(x, y)
$$

for all $x, y \in X$ where $\tau>0$. Now, since $\frac{1}{2(1+\tau)} \omega_{\lambda / l}(x, y) \leq \omega_{\lambda / 2 l}(x, y)$ for all $x, y \in X$, so $\eta(x, y) \leq \alpha(x, y)$ for all $x, y \in X$. That is, conditions (i) and (iii) of Theorem 2.2 hold true. Let $\left\{x_{n}\right\}$ be a sequence with $x_{n} \rightarrow x$ as $n \rightarrow \infty$. Assume that $\omega_{\lambda / l}\left(T x_{n}, T^{2} x_{n}\right)=0$ for some $n$. Then $T x_{n}=T^{2} x_{n}$. That is, $T x_{n}$ is a fixed point of $T$ and we have nothing to prove. Hence we assume $T x_{n} \neq T^{2} x_{n}$ for all $n \in \mathbb{N}$. Since $\frac{1}{2(1+\tau)} \omega_{\lambda / l}\left(T x_{n}, T^{2} x_{n}\right) \leq \omega_{\lambda / l}\left(T x_{n}, T^{2} x_{n}\right)$ for all $n \in \mathbb{N}$, from (3.2) we get

$$
F\left(\omega_{\lambda / l}\left(T^{2} x_{n}, T^{3} x_{n}\right)\right) \leq \tau+F\left(\omega_{\lambda / l}\left(T^{2} x_{n}, T^{3} x_{n}\right)\right) \leq F\left(\omega_{\lambda / l}\left(T x_{n}, T^{2} x_{n}\right)\right)
$$

and so from (F1) we get

$$
\omega_{\lambda / l}\left(T^{2} x_{n}, T^{3} x_{n}\right) \leq \omega_{\lambda / l}\left(T x_{n}, T^{2} x_{n}\right) .
$$

Suppose that there exists $n_{0} \in \mathbb{N}$ such that

$$
\eta\left(T x_{n_{0}}, T^{2} x_{n_{0}}\right)>\alpha\left(T x_{n_{0}}, x\right) \text { and } \eta\left(T^{2} x_{n_{0}}, T^{3} x_{n_{0}}\right)>\alpha\left(T^{2} x_{n_{0}}, x\right)
$$

then

$$
\begin{aligned}
& \frac{1}{2(1+\tau)} \omega_{\lambda / l}\left(T x_{n_{0}}, T^{2} x_{n_{0}}\right)>\omega_{\lambda / 2 l}\left(T x_{n_{0}}, x\right) \quad \text { and } \\
& \frac{1}{2(1+\tau)} \omega_{\lambda / l}\left(T^{2} x_{n_{0}}, T^{3} x_{n_{0}}\right)>\omega_{\lambda / 2 l}\left(T^{2} x_{n_{0}}, x\right),
\end{aligned}
$$

so by (3.3) we have

$$
\begin{aligned}
\omega_{\lambda / l}\left(T x_{n_{0}}, T^{2} x_{n_{0}}\right) & \leq \omega_{\lambda / 2 l}\left(T x_{n_{0}}, x\right)+\omega_{\lambda / 2 l}\left(T^{2} x_{n_{0}}, x\right) \\
& <\frac{1}{2(1+\tau)} \omega_{\lambda / l}\left(T x_{n_{0}}, T^{2} x_{n_{0}}\right)+\frac{1}{2(1+\tau)} \omega_{\lambda / l}\left(T^{2} x_{n_{0}}, T^{3} x_{n_{0}}\right) \\
& \leq \frac{1}{2(1+\tau)} \omega_{\lambda / l}\left(T x_{n_{0}}, T^{2} x_{n_{0}}\right)+\frac{1}{2(1+\tau)} \omega_{\lambda / l}\left(T x_{n_{0}}, T^{2} x_{n_{0}}\right) \\
& =\frac{2}{2(1+\tau)} \omega_{\lambda / l}\left(T x_{n_{0}}, T^{2} x_{n_{0}}\right) \leq \omega_{\lambda / l}\left(T x_{n_{0}}, T^{2} x_{n_{0}}\right),
\end{aligned}
$$

which is a contradiction. Hence, either

$$
\eta\left(T x_{n}, T^{2} x_{n}\right) \leq \alpha\left(T x_{n}, x\right) \quad \text { or } \quad \eta\left(T^{2} x_{n}, T^{3} x_{n}\right) \leq \alpha\left(T^{2} x_{n}, x\right)
$$

holds for all $n \in \mathbb{N}$. That is, condition (iv) of Theorem 2.2 holds. Let $\eta(x, T x) \leq \alpha(x, y)$. So, $\frac{1}{2(1+\tau)} \omega_{\lambda / l}(x, T x) \leq \omega_{\lambda / 2 l}(x, y)$. Then from (3.2) we get $\tau+F\left(\omega_{\lambda / l}(T x, T y)\right) \leq F\left(\omega_{\lambda / l}(x, y)\right)$. Hence, all conditions of Theorem 2.2 hold and $T$ has a unique fixed point. 


\section{Applications to orbitally continuous mappings}

Theorem 4.1 Let $X_{\omega}$ be a complete modular metric space and $T: X_{\omega} \rightarrow X_{\omega}$ be a selfmapping satisfying the following assertions:

(i) for $x, y \in O(z)$ with $\omega_{\lambda / l}(T x, T y)>0$ we have

$$
G\left(\omega_{\lambda / l}(x, T x), \omega_{\lambda / l}(y, T y), \omega_{\lambda / l}(x, T y), \omega_{\lambda / l}(y, T x)\right)+F\left(\omega_{\lambda / l}(T x, T y)\right) \leq F\left(\omega_{\lambda / l}(x, y)\right),
$$

where $G \in \Delta_{G}$ and $F \in \Delta_{F}$;

(ii) $T$ is an orbitally continuous function.

Then $T$ has a fixed point. Moreover, T has a unique fixed point when $\operatorname{Fix}(T) \subseteq O(z)$.

Proof Define, $\alpha, \eta: X \times X \rightarrow[0,+\infty)$ by

$$
\alpha(x, y)=\left\{\begin{array}{ll}
3, & \text { if } x, y \in O(z), \\
0, & \text { otherwise }
\end{array} \quad \text { and } \quad \eta(x, y)=1\right.
$$

where $O(z)$ is an orbit of a point $z \in X$. From Remark 1.1 we know that $T$ is an $\alpha$ $\eta$-continuous mapping. Let $\alpha(x, y) \geq \eta(x, y)$, then $x, y \in O(z)$. So $T x, T y \in O(z)$. That is, $\alpha(T x, T y) \geq \eta(T x, T y)$. Therefore, $T$ is an $\alpha$-admissible mapping with respect to $\eta$. Since $z, T z \in O(z), \alpha(z, T z) \geq \eta(z, T z)$. Let $\alpha(x, y) \geq \eta(x, T x)$ and $\omega_{\lambda / l}(T x, T y)>0$. Then $x, y \in O(z)$ and $\omega_{\lambda / l}(T x, T y)>0$. Therefore from (i) we have

$$
G\left(\omega_{\lambda / l}(x, T x), \omega_{\lambda / l}(y, T y), \omega_{\lambda / l}(x, T y), \omega_{\lambda / l}(y, T x)\right)+F\left(\omega_{\lambda / l}(T x, T y)\right) \leq F\left(\omega_{\lambda / l}(x, y)\right),
$$

which implies that $T$ is an $\alpha-\eta$-GF-contraction mapping. Hence, all conditions of Theorem 2.1 hold true and $T$ has a fixed point. If $\operatorname{Fix}(T) \subseteq O(z)$, then $\alpha(x, y) \geq \eta(x, y)$ for all $x, y \in \operatorname{Fix}(T)$ and so from Theorem $2.1 T$ has a unique fixed point.

Corollary 4.1 Let $X_{\omega}$ be a complete modular metric space and $T: X_{\omega} \rightarrow X_{\omega}$ be a selfmapping satisfying the following assertions:

(i) for $x, y \in O(z)$ with $\omega_{\lambda / l}(T x, T y)>0$ we have

$$
\tau+F\left(\omega_{\lambda / l}(T x, T y)\right) \leq F\left(\omega_{\lambda / l}(x, y)\right)
$$

where $\tau>0$ and $F \in \Delta_{F}$;

(ii) $T$ is orbitally continuous.

Then $T$ has a fixed point. Moreover, $T$ has a unique fixed point when $\operatorname{Fix}(T) \subseteq O(z)$.

Corollary 4.2 Let $X_{\omega}$ be a complete modular metric space and $T: X_{\omega} \rightarrow X_{\omega}$ be a selfmapping satisfying the following assertions:

(i) for $x, y \in O(z)$ with $\omega_{\lambda / l}(T x, T y)>0$ we have

$$
\tau e^{L \min \left\{\omega_{\lambda / l}(x, T x), \omega_{\lambda / l}(y, T y), \omega_{\lambda / l}(x, T y), d(y, T x)\right\}}+F\left(\omega_{\lambda / l}(T x, T y)\right) \leq F\left(\omega_{\lambda / l}(x, y)\right),
$$

where $\tau>0, L \geq 0$, and $F \in \Delta_{F} ;$

(ii) $T$ is orbitally continuous.

Then $T$ has a fixed point. Moreover, $T$ has a unique fixed point when $\operatorname{Fix}(T) \subseteq O(z)$. 
Theorem 4.2 Let $X_{\omega}$ be a complete modular metric space and $T: X_{\omega} \rightarrow X_{\omega}$ be a selfmapping satisfying the following assertions:

(i) for $x \in X$ with $\omega_{\lambda / l}\left(T x, T^{2} x\right)>0$ we have

$$
\tau+F\left(\omega_{\lambda / l}\left(T x, T^{2} x\right)\right) \leq F\left(\omega_{\lambda / l}(x, T x)\right)
$$

where $\tau>0$ and $F \in \Delta_{F}$;

(ii) $T$ is an orbitally continuous function.

Then $T$ has the property $P$.

Proof Define, $\alpha: X \times X \rightarrow[0,+\infty)$ by

$$
\alpha(x, y)= \begin{cases}1, & \text { if } x \in O(z) \\ 0, & \text { otherwise }\end{cases}
$$

where $z \in X$. Let $\alpha(x, y) \geq 1$, then $x, y \in O(z)$. So $T x, T y \in O(z)$. That is, $\alpha(T x, T y) \geq 1$. Therefore, $T$ is $\alpha$-admissible mapping. Since $z, T z \in O(z), \alpha(z, T z) \geq 1$. By Remark 1.1 we conclude that $T$ is an $\alpha$-continuous mapping. If $x \in X$ with $\omega_{\lambda / l}\left(T x, T^{2} x\right)>0$, then, from (i), we have

$$
\tau+F\left(\omega_{\lambda / l}\left(T x, T^{2} x\right)\right) \leq F\left(\omega_{\lambda / l}(x, T x)\right) .
$$

Thus all conditions of Theorem 2.3 hold true and $T$ has the property $P$.

\section{Fixed point results for integral type contractions}

Recently, Azadifar et al. [29] and Razani and Moradi [30] proved common fixed point theorems for integral type contractions in modular metric spaces. In this section, we deduce more general fixed point theorems for integral type $G F$-contractions.

Theorem 5.1 Let $X_{\omega}$ be a complete modular metric space. Let $T: X_{\omega} \rightarrow X_{\omega}$ be a selfmapping satisfying the following assertions:

(i) $T$ is an $\alpha$-admissible mapping with respect to $\eta$;

(ii) there exists $x_{0} \in X_{\omega}$ such that $\alpha\left(x_{0}, T x_{0}\right) \geq \eta\left(x_{0}, T x_{0}\right)$;

(iii) $T$ is $\alpha$ - $\eta$-continuous;

(iv) there exist $G \in \Delta_{G}, F \in \Delta_{F}$ such that for all $x, y \in X_{\omega}$ and $\lambda>0$

$$
\begin{aligned}
& G\left(\int_{0}^{\omega_{\lambda / l}(x, T x)} \rho(t) d t, \int_{0}^{\omega_{\lambda / l}(y, T y)} \rho(t) d t, \int_{0}^{\omega_{\lambda / l}(x, T y)} \rho(t) d t, \int_{0}^{\omega_{\lambda / l}(y, T x)} \rho(t) d t\right) \\
& \quad+F\left(\int_{0}^{\omega_{\lambda / l}(T x, T y)} \rho(t) d t\right) \leq F\left(\int_{0}^{\omega_{\lambda / l}(x, y)} \rho(t) d t\right),
\end{aligned}
$$

where $\rho:[0, \infty) \rightarrow[0, \infty)$ is a Lebesgue-integrable mapping satisfying $\int_{0}^{\varepsilon} \rho(t) d t>0$ for $\varepsilon>0$.

Then $T$ has a fixed point. Moreover, $T$ has a unique fixed point when $\alpha(x, y) \geq \eta(x, x)$ for all $x, y \in \operatorname{Fix}(T)$.

Theorem 5.2 Let $X_{\omega}$ be a complete modular metric space. Let $T: X_{\omega} \rightarrow X_{\omega}$ be a selfmapping satisfying the following assertions: 
(i) $T$ is an $\alpha$-admissible mapping with respect to $\eta$;

(ii) there exists $x_{0} \in X_{\omega}$ such that $\alpha\left(x_{0}, T x_{0}\right) \geq \eta\left(x_{0}, T x_{0}\right)$;

(iii) if $\left\{x_{n}\right\}$ is a sequence in $X_{\omega}$ such that $\alpha\left(x_{n}, x_{n+1}\right) \geq \eta\left(x_{n}, x_{n+1}\right)$ with $x_{n} \rightarrow x$ as $n \rightarrow \infty$, then either

$$
\eta\left(T x_{n}, T^{2} x_{n}\right) \leq \alpha\left(T x_{n}, x\right) \quad \text { or } \quad \eta\left(T^{2} x_{n}, T^{3} x_{n}\right) \leq \alpha\left(T^{2} x_{n}, x\right)
$$

holds for all $n \in \mathbb{N}$;

(iv) condition (iv) of Theorem 5.1 holds.

Then $T$ has a fixed point. Moreover, T has a unique fixed point whenever $\alpha(x, y) \geq \eta(x, x)$ for all $x, y \in \operatorname{Fix}(T)$.

Theorem 5.3 Let $X_{\omega}$ be a complete modular metric space and $T$ be a continuous selfmapping on $X_{\omega}$. Assume for $x, y \in X$ with

$$
\int_{0}^{\omega_{\lambda / l}(x, T x)} \rho(t) d t \leq \int_{0}^{\omega_{\lambda / l}(x, y)} \rho(t) d t \text { and } \int_{0}^{\omega_{\lambda / l}(T x, T y)} \rho(t) d t>0
$$

we have

$$
\begin{aligned}
& G\left(\int_{0}^{\omega_{\lambda / l}(x, T x)} \rho(t) d t, \int_{0}^{\omega_{\lambda / l}(y, T y)} \rho(t) d t, \int_{0}^{\omega_{\lambda / l}(x, T y)} \rho(t) d t, \int_{0}^{\omega_{\lambda / l}(y, T x)} \rho(t) d t\right) \\
& \quad+F\left(\int_{0}^{\omega_{\lambda / l}(T x, T y)} \rho(t) d t\right) \leq F\left(\int_{0}^{\omega_{\lambda / l}(x, y)} \rho(t) d t\right),
\end{aligned}
$$

where $G \in \Delta_{G}, F \in \Delta_{F}$, and $\rho:[0, \infty) \rightarrow[0, \infty)$ is a Lebesgue-integrable mapping satisfying $\int_{0}^{\varepsilon} \rho(t) d t>0$ for $\varepsilon>0$. Then $T$ has a unique fixed point.

Theorem 5.4 Let $X_{\omega}$ be a complete modular metric space and $T$ be a self-mapping on $X_{\omega}$. Assume that there exists $\tau>0$ such that

$$
\begin{aligned}
& \frac{1}{2(1+\tau)} \int_{0}^{\omega_{\lambda / l}(x, T x)} \rho(t) d t \leq \int_{0}^{\omega_{\lambda / 2 l}(x, y)} \rho(t) d t \\
& \quad \Rightarrow \quad \tau+F\left(\int_{0}^{\omega_{\lambda / l}(T x, T y)} \rho(t) d t\right) \leq F\left(\int_{0}^{\omega_{\lambda / l}(x, y)} \rho(t) d t\right)
\end{aligned}
$$

for $x, y \in X$ with $\int_{0}^{\omega_{\lambda / l}(T x, T y)} \rho(t) d t>0$ where $F \in \Delta_{F}$ and $\rho:[0, \infty) \rightarrow[0, \infty)$ is a Lebesgueintegrable mapping satisfying $\int_{0}^{\varepsilon} \rho(t) d t>0$ for $\varepsilon>0$. Then $T$ has a unique fixed point.

Theorem 5.5 Let $X_{\omega}$ be a complete modular metric space and $T: X_{\omega} \rightarrow X_{\omega}$ be a selfmapping satisfying the following assertions:

(i) for $x, y \in O(z)$ with $\int_{0}^{\omega_{\lambda / l}(T x, T y)} \rho(t) d t>0$ we have

$$
\begin{aligned}
& G\left(\int_{0}^{\omega_{\lambda / l}(x, T x)} \rho(t) d t, \int_{0}^{\omega_{\lambda / l}(y, T y)} \rho(t) d t, \int_{0}^{\omega_{\lambda / l}(x, T y)} \rho(t) d t, \int_{0}^{\omega_{\lambda / l}(y, T x)} \rho(t) d t\right) \\
& \quad+F\left(\int_{0}^{\omega_{\lambda / l}(T x, T y)} \rho(t) d t\right) \leq F\left(\int_{0}^{\omega_{\lambda / l}(x, y)} \rho(t) d t\right),
\end{aligned}
$$


where $G \in \Delta_{G}, F \in \Delta_{F}$, and $\rho:[0, \infty) \rightarrow[0, \infty)$ is a Lebesgue-integrable mapping satisfying $\int_{0}^{\varepsilon} \rho(t) d t>0$ for $\varepsilon>0$.

(ii) $T$ is an orbitally continuous function;

Then $T$ has a fixed point. Moreover, $T$ has a unique fixed point when $\operatorname{Fix}(T) \subseteq O(w)$.

Theorem 5.6 Let $X_{\omega}$ be a complete modular metric space and $T: X_{\omega} \rightarrow X_{\omega}$ be a selfmapping satisfying the following assertions:

(i) for $x \in X$ with $\int_{0}^{\omega_{\lambda / l}\left(T x, T^{2} x\right)} \rho(t) d t>0$ we have

$$
\tau+F\left(\int_{0}^{\omega_{\lambda / l}\left(T x, T^{2} x\right)} \rho(t) d t\right) \leq F\left(\int_{0}^{\omega_{\lambda / l}(x, T x)} \rho(t) d t\right)
$$

where $\tau>0$ and $F \in \Delta_{F}$ and $\rho:[0, \infty) \rightarrow[0, \infty)$ is a Lebesgue-integrable mapping satisfying $\int_{0}^{\varepsilon} \rho(t) d t>0$ for $\varepsilon>0$.

(ii) $T$ is an orbitally continuous function.

Then $T$ has the property $P$.

\section{Modular metric spaces to fuzzy metric spaces}

In 1988, Grabiec [31] defined contractive mappings on a fuzzy metric space and extended fixed point theorems of Banach and Edelstein in such spaces. Successively, George and Veeramani [32] slightly modified the notion of a fuzzy metric space introduced by Kramosil and Michálek and then defined a Hausdorff and first countable topology on it. Then the notion of a complete fuzzy metric space presented by George and Veeramani has emerged as another characterization of completeness, and many fixed point theorems have also been proved (for more details see [33-42] and the references therein). In this section we deduce fixed point results in a triangular fuzzy metric space.

Definition 6.1 [32] The 3-tuple $(X, M, *)$ is said to be a fuzzy metric space if $X$ is an arbitrary nonempty set, $*$ is a continuous $t$-norm and $M$ is a fuzzy set in $X^{2} \times(0, \infty)$ satisfying the following conditions: for all $x, y, z \in X, s, t>0$,

(1) $M(x, y, t)>0$,

(2) $M(x, y, t)=1$ iff $x=y$,

(3) $M(x, y, t)=M(y, x, t)$,

(4) $M(x, y, t) * M(y, z, s) \leq M(x, z, t+s)$,

(5) $M(x, y, \cdot):(0, \infty) \rightarrow[0,1]$ is continuous.

The function $M(x, y, t)$ denotes the degree of nearness between $x$ and $y$ with respect to $t$.

Definition 6.2 [34] Let $(X, M, *)$ be a fuzzy metric space. The fuzzy metric $M$ is called triangular whenever

$$
\frac{1}{M(x, y, t)}-1 \leq \frac{1}{M(x, z, t)}-1+\frac{1}{M(z, y, t)}-1
$$

for all $x, y, z \in X$ and all $t>0$.

Example 6.1 Let $X=\mathbb{R}^{2}$. Define $M$ on $X \times X \times(0, \infty)$ by $M\left(\left(x_{1}, x_{2}\right),\left(y_{1}, y_{2}\right), t\right)=$ $\frac{1}{1+\left|x_{1}-y_{1}\right|+\left|x_{2}-y_{2}\right|}$ and $a \star b=\min \{a, b\}$. Then $(M, X, \star)$ is a triangular fuzzy metric space. 
Further if $X=\mathbb{R}$ and $M$ on $X \times X \times(0, \infty)$ is defined by $M(x, y, t)=\min \{x, y\} / \max \{x, y\}$ and $a \star b=\min \{a, b\}$. Then $(M, X, \star)$ is a non-triangular fuzzy metric space.

Lemma 6.1 $[31,33]$ For all $x, y \in X, M(x, y, \cdot)$ is non-deceasing on $(0, \infty)$.

Lemma 6.2 ([40], Lemma 34) Let $(X, M, *)$ be a triangular fuzzy metric space. Define

$$
\omega_{\lambda}(x, y)=\frac{1}{M(x, y, \lambda)}-1
$$

for all $x, y \in X$ and all $\lambda>0$. Then $\omega_{\lambda}$ is a modular metric on $X$.

As an application of Lemma 6.2 and the results proved above we deduce the following new fixed point theorems in triangular fuzzy metric spaces.

Theorem 6.1 Let $(X, M, *)$ be a complete triangular fuzzy metric space. Let $T: X \rightarrow X$ be a self-mapping satisfying the following assertions:

(i) $T$ is an $\alpha$-admissible mapping with respect to $\eta$;

(ii) there exists $x_{0} \in X_{\omega}$ such that $\alpha\left(x_{0}, T x_{0}\right) \geq \eta\left(x_{0}, T x_{0}\right)$;

(iii) $T$ is $\alpha$ - $\eta$-continuous;

(iv) for $x, y \in X$ with $\eta(x, T x) \leq \alpha(x, y), M(T x, T y, \lambda / l)>0$, we have

$$
\begin{aligned}
& G\left(\frac{1}{M(x, T x, \lambda / l)}-1, \frac{1}{M(y, T y, \lambda / l)}-1, \frac{1}{M(x, T y, \lambda / l)}-1\right. \\
& \left.\quad \frac{1}{M(y, T x, \lambda / l)}-1\right)+F\left(\frac{1}{M(T x, T y, \lambda / l)}-1\right) \leq F\left(\frac{1}{M(x, y, \lambda / l)}-1\right)
\end{aligned}
$$

where $G \in \Delta_{G}$ and $F \in \Delta_{F}$.

Then $T$ has a fixed point. Moreover, $T$ has a unique fixed point when $\alpha(x, y) \geq \eta(x, x)$ for all $x, y \in \operatorname{Fix}(T)$.

Theorem 6.2 Let $(X, M, *)$ be a complete triangular fuzzy metric space. Let $T: X \rightarrow X$ be a self-mapping satisfying the following assertions:

(i) $T$ is an $\alpha$-admissible mapping with respect to $\eta$;

(ii) there exists $x_{0} \in X_{\omega}$ such that $\alpha\left(x_{0}, T x_{0}\right) \geq \eta\left(x_{0}, T x_{0}\right)$;

(iii) if $\left\{x_{n}\right\}$ is a sequence in $X_{\omega}$ such that $\alpha\left(x_{n}, x_{n+1}\right) \geq \eta\left(x_{n}, x_{n+1}\right)$ with $x_{n} \rightarrow x$ as $n \rightarrow \infty$, then either

$$
\eta\left(T x_{n}, T^{2} x_{n}\right) \leq \alpha\left(T x_{n}, x\right) \quad \text { or } \quad \eta\left(T^{2} x_{n}, T^{3} x_{n}\right) \leq \alpha\left(T^{2} x_{n}, x\right)
$$

holds for all $n \in \mathbb{N}$;

(iv) condition (iv) of Theorem 6.1 holds.

Then $T$ has a fixed point. Moreover, $T$ has a unique fixed point whenever $\alpha(x, y) \geq \eta(x, x)$ for all $x, y \in \operatorname{Fix}(T)$.

Theorem 6.3 Let $(X, M, *)$ be a complete triangular fuzzy metric space and $T: X \rightarrow X$ be an $\alpha$-continuous self-mapping. Assume that there exists $\tau>0$ such that

$$
\tau+F\left(\frac{1}{M\left(T x, T^{2} x, \lambda / l\right)}-1\right) \leq F\left(\frac{1}{M(x, T x, \lambda / l)}-1\right)
$$


holds for all $x \in X$ with $M\left(T x, T^{2} x, \lambda / l\right)>0$ where $F \in \Delta_{F}$. If $T$ is an $\alpha$-admissible mapping and there exists $x_{0} \in X_{\omega}$ such that $\alpha\left(x_{0}, T x_{0}\right) \geq 1$, then $T$ has the property $P$.

Theorem 6.4 Let $(X, M, *, \preceq)$ be a complete partially ordered triangular fuzzy metric space. Assume that the following assertions hold true:

(i) $T$ is nondecreasing;

(ii) there exists $x_{0} \in X$ such that $x_{0} \preceq T x_{0}$;

(iii) either for a given $x \in X$ and sequence $\left\{x_{n}\right\}$

$$
x_{n} \rightarrow x \text { as } n \rightarrow \infty \text { and } x_{n} \preceq x_{n+1} \text { for all } n \in \mathbb{N} \text { we have } T x_{n} \rightarrow T x
$$

or if $\left\{x_{n}\right\}$ is a sequence such that $x_{n} \preceq x_{n+1}$ with $x_{n} \rightarrow x$ as $n \rightarrow \infty$, then either

$$
T x_{n} \preceq x \text { or } \quad T^{2} x_{n} \preceq x
$$

holds for all $n \in \mathbb{N}$;

(iv) for $x, y \in X$ with $x \preceq y \eta(x, T x) \leq \alpha(x, y), M(T x, T y, \lambda / l)>0$, we have

$$
\begin{aligned}
& G\left(\frac{1}{M(x, T x, \lambda / l)}-1, \frac{1}{M(y, T y, \lambda / l)}-1, \frac{1}{M(x, T y, \lambda / l)}-1\right. \\
& \left.\quad \frac{1}{M(y, T x, \lambda / l)}-1\right)+F\left(\frac{1}{M(T x, T y, \lambda / l)}-1\right) \leq F\left(\frac{1}{M(x, y, \lambda / l)}-1\right)
\end{aligned}
$$

where $G \in \Delta_{G}$ and $F \in \Delta_{F}$.

Then $T$ has a fixed point.

Theorem 6.5 Let $(X, M, *, \preceq)$ be a complete partially ordered triangular fuzzy metric space. Assume that the following assertions hold true:

(i) $T$ is nondecreasing;

(ii) there exists $x_{0} \in X$ such that $x_{0} \preceq T x_{0}$;

(iii) $T$ is continuous;

(iv) for $x, y \in X$ with $x \preceq y \eta(x, T x) \leq \alpha(x, y), M(T x, T y, \lambda / l)>0$, we have

$$
\begin{aligned}
& G\left(\frac{1}{M(x, T x, \lambda / l)}-1, \frac{1}{M(y, T y, \lambda / l)}-1, \frac{1}{M(x, T y, \lambda / l)}-1\right. \\
& \left.\quad \frac{1}{M(y, T x, \lambda / l)}-1\right)+F\left(\frac{1}{M(T x, T y, \lambda / l)}-1\right) \leq F\left(\frac{1}{M(x, y, \lambda / l)}-1\right)
\end{aligned}
$$

where $G \in \Delta_{G}$ and $F \in \Delta_{F}$.

Then $T$ has a fixed point.

Theorem 6.6 Let $(X, M, *)$ be a complete triangular fuzzy metric space and $T$ be a continuous self-mapping on $X$. Assume for $x, y \in X$ with $\frac{1}{M(x, T x, \lambda / l)} \leq \frac{1}{M(x, y, \lambda / l)}$ and $\frac{1}{M(T x, T y, \lambda / l)}>0$ we have 


$$
\begin{aligned}
& G\left(\frac{1}{M(x, T x, \lambda / l)}-1, \frac{1}{M(y, T y, \lambda / l)}-1, \frac{1}{M(x, T y, \lambda / l)}-1, \frac{1}{M(y, T x, \lambda / l)}-1\right) \\
& \quad+F\left(\frac{1}{M(T x, T y, \lambda / l)}-1\right) \leq F\left(\frac{1}{M(x, y, \lambda / l)}-1\right)
\end{aligned}
$$

where $G \in \Delta_{G}$ and $F \in \Delta_{F}$. Then $T$ has a unique fixed point.

Theorem 6.7 Let $(X, M, *)$ be a complete triangular fuzzy metric space and $T$ be a selfmapping on $X$. Assume that there exists $\tau>0$ such that

$$
\begin{aligned}
& \frac{1}{2(1+\tau)}\left(\frac{1}{M(x, T x, \lambda / l)}-1\right) \leq \frac{1}{M(x, y, \lambda / 2 l)}-1 \\
& \text { implies } \tau+F\left(\frac{1}{M(T x, T y, \lambda / l)}-1\right) \leq F\left(\frac{1}{M(x, y, \lambda / l)}-1\right)
\end{aligned}
$$

for $x, y \in X$ with $\frac{1}{M(T x, T y, \lambda / l)}>0$ where $F \in \Delta_{F}$. Then $T$ has a unique fixed point.

\section{Competing interests}

The authors declare that there is no conflict of interests regarding the publication of this article.

\section{Authors' contributions}

All authors contributed equally and significantly in writing this article. All authors read and approve the final manuscript.

\section{Author details}

'Department of Mathematics, King Abdulaziz University, P.O. Box 80203, Jeddah, 21589, Saudi Arabia. ${ }^{2}$ Department of Mathematics, University of Sargodha, Sargodha, Pakistan.

\section{Acknowledgements}

This article was funded by the Deanship of Scientific Research (DSR), King Abdulaziz University, Jeddah. The authors, therefore, acknowledge with thanks DSR technical and financial support. Finally, the authors thank the honorable reviewers for their valuable comments and suggestions.

\section{Received: 27 May 2015 Accepted: 17 August 2015 Published online: 02 September 2015}

\section{References}

1. Nakano, H: Modulared Semi-Ordered Linear Spaces. Maruzen, Tokyo (1950)

2. Musielak, J, Orlicz, W: On modular spaces. Stud. Math. 18, 49-65 (1959)

3. Musielak, J, Orlicz, W: Some remarks on modular spaces. Bull. Acad. Pol. Sci., Sér. Sci. Math. Astron. Phys. 7, 661-668 (1959)

4. Chistyakov, W: Modular metric spaces, I: basic concepts. Nonlinear Anal., Theory Methods Appl. 72(1), 1-14 (2010)

5. Chistyakov, W: Modular metric spaces, II: application to superposition operators. Nonlinear Anal., Theory Methods Appl. 72(1), 15-30 (2010)

6. Khamsi, MA, Kozlowski, WK, Reich, S: Fixed point theory in modular function spaces. Nonlinear Anal. 14(11), 935-953 (1990)

7. Abdou, AAN, Khamsi, MA: Fixed points of multivalued contraction mappings in modular metric spaces. Fixed Point Theory Appl. 2014, Article ID 249 (2014)

8. Azadifar, B, Maramaei, M, Sadeghi, G: On the modular G-metric spaces and fixed point theorems. J. Nonlinear Sci. Appl. 6(4), 293-304 (2013)

9. Chaipunya, $\mathrm{P}, \mathrm{Cho}, \mathrm{YJ}$, Kumam, P: Geraghty-type theorems in modular metric spaces with an application to partial differential equation. Fixed Point Theory Appl. 2012, Article ID 83 (2012)

10. Chistyakov, W: A fixed point theorem for contractions in modular metric spaces. Preprint submited to arXiv:1112.5561 (2011)

11. Chaipunya, P, Mongkolkeha, C, Sintunavarat, W, Kumam, P: Fixed-point theorems for multivalued mappings in modular metric spaces. Abstr. Appl. Anal. 2012, Article ID 503504 (2012)

12. Mongkolkeha, C, Sintunavarat, W, Kumam, P: Fixed point theorem for contraction mappings in modular metric spaces. Fixed Point Theory Appl. 2011, Article ID 93 (2011). doi:10.1186/1687-1812-2011-93

13. Wardowski, D: Fixed points of a new type of contractive mappings in complete metric spaces. Fixed Point Theory Appl. 2012, Article ID 94 (2012)

14. Hussain, N, Salimi, P: Suzuki-Wardowski type fixed point theorems for $\alpha$-GF-contractions. Taiwan. J. Math. 18(6), 1879-1895 (2014)

15. Hussain, N, Salimi, P, Parvaneh, V: Fixed point results for various contractions in parametric and fuzzy b-metric spaces. J. Nonlinear Sci. Appl. 8(5), 719-739 (2015)

16. Hussain, N, Hezarjaribi, M, Salimi, P: Suzuki type theorems in triangular and non-Archimedean fuzzy metric spaces with application. Fixed Point Theory Appl. 2015, Article ID 134 (2015) 
17. Sgroi, M, Vetro, C: Multi-valued F-contractions and the solution of certain functional and integral equations. Filomat 27(7), 1259-1268 (2013)

18. Samet, B, Vetro, C, Vetro, P: Fixed point theorems for $\alpha$ - $\psi$-contractive type mappings. Nonlinear Anal. 75, 2154-2165 (2012)

19. Salimi, P, Latif, A, Hussain, N: Modified $\alpha$ - $\psi$-contractive mappings with applications. Fixed Point Theory Appl. 2013, Article ID 151 (2013)

20. Hussain, N, Kutbi, MA, Salimi, P: Fixed point theory in $\alpha$-complete metric spaces with applications. Abstr. Appl. Anal. 2014, Article ID 280817 (2014)

21. Hussain, N, Ahmad, J, Azam, A: On Suzuki-Wardowski type fixed point theorems. J. Nonlinear Sci. Appl. 8, 1095-1111 (2015)

22. Agarwal, RP, Hussain, N, Taoudi, MA: Fixed point theorems in ordered Banach spaces and applications to nonlinear integral equations. Abstr. Appl. Anal. 2012, Article ID 245872 (2012)

23. Ansari, QH, Idzik, A, Yao, JC: Coincidence and fixed point theorems with applications. Topol. Methods Nonlinear Anal. 15(1), 191-202 (2000)

24. Hussain, N, Al-Mezel, S, Salimi, P: Fixed points for $\psi$-graphic contractions with application to integral equations. Abstr. Appl. Anal. 2013, Article ID 575869 (2013)

25. Hussain, N, Aziz Taoudi, M: Krasnosel'skii-type fixed point theorems with applications to Volterra integral equations. Fixed Point Theory Appl. 2013, Article ID 196 (2013)

26. Nieto, JJ, Rodríguez-López, R: Contractive mapping theorems in partially ordered sets and applications to ordinary differential equations. Order 22, 223-229 (2005)

27. Suzuki, T: A new type of fixed point theorem in metric spaces. Nonlinear Anal. 71(11), 5313-5317 (2009)

28. Suzuki, T: A generalized Banach contraction principle that characterizes metric completeness. Proc. Am. Math. Soc. 136, 1861-1869 (2008)

29. Azadifar, B, Sadeghi, G, Saadati, R, Park, C: Integral type contractions in modular metric spaces. J. Inequal. Appl. 2013, Article ID 483 (2013)

30. Razani, A, Moradi, R: Common fixed point theorems of integral type in modular spaces. Bull. Iran. Math. Soc. 35(2), 11-24 (2009)

31. Grabiec, M: Fixed points in fuzzy metric spaces. Fuzzy Sets Syst. 27(3), 385-389 (1988)

32. George, A, Veeramani, P: On some results in fuzzy metric spaces. Fuzzy Sets Syst. 64, 395-399 (1994)

33. Altun, I, Turkoglu, D: Some fixed point theorems on fuzzy metric spaces with implicit relations. Commun. Korean Math. Soc. 23(23), 111-124 (2008)

34. di Bari, C, Vetro, C: A fixed point theorem for a family of mappings in a fuzzy metric space. Rend. Circ. Mat. Palermo 52(2), 315-321 (2003)

35. Chauhan, S, Shatanawi, W, Kumar, S, Radenovic, S: Existence and uniqueness of fixed points in modified intuitionistic fuzzy metric spaces. J. Nonlinear Sci. Appl. 7(1), 28-41 (2014)

36. Gopal, D, Imdad, M, Vetro, C, Hasan, M: Fixed point theory for cyclic weak $\phi$-contraction in fuzzy metric spaces. J. Nonlinear Anal. Appl. 2012, Article ID jnaa-001 10 (2012)

37. Hussain, N, Khaleghizadeh, S, Salimi, P, Abdou, ANA: A new approach to fixed point results in triangular intuitionistic fuzzy metric spaces. Abstr. Appl. Anal. 2014, Article ID 690139 (2014)

38. Kutbi, MA, Ahmad, J, Azam, A, Hussain, N: On fuzzy fixed points for fuzzy maps with generalized weak property. J. Appl. Math. 2014, Article ID 549504 (2014)

39. Mihet, D: Common coupled fixed point theorems for contractive mappings in fuzzy metric spaces. J. Nonlinear Sci. Appl. 6(1), 35-40 (2013)

40. Hussain, N, Salimi, P: Implicit contractive mappings in modular metric and fuzzy metric spaces. Sci. World J. 2014 Article ID 981578 (2014)

41. Ciric, L, Mihet, D, Saadati, R: Monotone generalized contractions in partially ordered probabilistic metric spaces. Topol. Appl. 156, 2838-2844 (2009)

42. Hussain, N, Kutbi, MA, Khaleghizadeh, S, Salimi, P: Discussions on recent results for $\alpha$ - $\psi$-contractive mappings. Abstr. Appl. Anal. 2014, Article ID 456482 (2014)

\section{Submit your manuscript to a SpringerOpen ${ }^{\circ}$ journal and benefit from:}

- Convenient online submission

Rigorous peer review

- Immediate publication on acceptance

- Open access: articles freely available online

- High visibility within the field

- Retaining the copyright to your article 